\title{
LA MONTAÑA ACUMULADA. LA JURISDICCIÓN DE RESPONSABILIDADES POLÍTICAS EN VALENCIA HASTA LA REFORMA DE 1942 (1)
}

\author{
MÉLANIE IBÁÑEZ DOMINGO \\ Universidad de Valencia \\ melanie.ibanez@uv.es
}

(Recepción: 15/05/2015; Revisión: 13/07/2015; Aceptación: 19/11/2015; Publicación: 02/12/2016)

\begin{abstract}
1. El AFÁN REPRESIVO DE UNA ABERRACIÓN JURÍDICA.-2. LOS INICIOS DE LA MONTAÑA. LA FORMACIÓN DEL TRIBUNAL REgIONAL DE VALENCIA.-3. LA MONTAÑA ACUMULADA. LA aCtuación de los Juzgados Instructores.-4. Consideraciones finales: LA CADENA DEL COLAPSO.-5. BIBLIOGRAFÍA
\end{abstract}

\begin{abstract}
RESUMEN
En apenas dos años la jurisdicción de Responsabilidades Políticas se convirtió en un problema a nivel estatal. Una montaña de causas pendientes de cumplir distintos trámites del procedimiento se acumulaba en los Tribunales Regionales y Juzgados Instructores. El objetivo de este trabajo es abordar los distintos factores que pudieron contribuir al rápido colapso de la jurisdicción especial encargada de aplicar la ley en la provincia de Valencia hasta la reforma de 1942. Para ello se analizará la formación y actuaciones de los organismos competentes territoriales en esta primera etapa de la Ley de Responsabilidades Políticas atendiendo sobre todo a las tres primeras fases del procedimiento: la orden del Tribunal Regional, la incoación efectiva de los Juzgados Instructores y la instrucción de los expedientes.
\end{abstract}

Palabras clave: Ley de Responsabilidades Políticas; Valencia; colapso; factores; fases del procedimiento.

(1) El presente trabajo forma parte del proyecto HAR 2014-57392: Transiciones, movimientos sociales y democracia en el siglo XX. España en perspectiva comparada. Financiado por el Ministerio de Economía y Competitividad y fondos FEDER. 


\title{
AN ACCUMULATED MOUNTAIN. THE JURISDICTION \\ OF RESPONSABILIDADES POLÍTICAS \\ IN VALENCIA UNTIL THE REFORM IN 1942
}

\begin{abstract}
In barely two years the jurisdiction of Responsabilidades Políticas became a statewide problem. A mountain of unresolved cases with pending bureaucratic procedures were accumulated in courts. This paper seeks to look into the contributing factors in the rapid collapse of this special jurisdiction in the province of Valencia until the reform in 1942. In order to this end, this paper analyze the creation and the interventions of competent bodies in Ley de Responsabilidades Políticas' first phase; especially focus is put on three stages of the process: the Court order, the commencement of the judicial proceedings and the examination of the files.
\end{abstract}

Keywords: Ley de Responsabilidades Políticas; Valencia; collapse; factors; stages of proceedings.

$$
* \quad * \quad *
$$

\section{EL AFÁN REPRESIVO DE UNA ABERRACIÓN JURÍDICA}

Tras un proceso de gestación nada fácil, el 9 de febrero de 1939 -aún no finalizada la Guerra Civil- fue aprobada la Ley de Responsabilidades Políticas (2). Heredera del Decreto 108 (septiembre de 1936) y del Decreto-Ley de enero de 1937, la nueva legislación «confirmaba y ampliaba» estas medidas previas de incautación y represión económica aplicadas en los territorios bajo control de los sublevados (3). En ellos, la jurisdicción de Responsabilidades Políticas sustituiría y continuaría la labor de requisa organizada. En aquellos territorios donde no actuó previamente la Incautación de Bienes - caso de la provincia de Valencia- los nuevos organismos creados ex profeso por la ley debían iniciar la tarea de cero.

Según su preámbulo debía servir para «liquidar las culpas» de todos aquellos que habían contribuido a «forjar» $\mathrm{y}$ «mantener viva» la «subversión roja» obstaculizando el «triunfo» del denominado «Movimiento Nacional» (4). Entre sus múltiples acepciones, el término liquidar se define como «saldar, pagar

(2) Sobre el proceso de discusión, debate y gestación de esta ley véase ÁLVARO (2006): 84-97.

(3) Langarita, Moreno y Murillo (2014): 42.

(4) La Ley de Responsabilidades Políticas (en adelante LRP) fue publicada en el Boletín Oficial del Estado (en adelante BOE) el 13 de febrero de 1939. Puede consultarse también en los Boletines Oficiales Provinciales o por internet. Entre otras, en la página web de la Universidad de 
enteramente una deuda». Deuda, cuenta, con un sentido económico en este y otros significados del término (5). El objetivo recaudatorio de la nueva jurisdicción está fuera de toda duda. Las sanciones económicas debían imponerse siempre y eran las únicas transmisibles e imprescriptibles. Quedaba «al prudente arbitrio de los Tribunales» la posibilidad de imponer otras, relativas a la restricción de la actividad o limitativas de la libertad de residencia (6). Por su parte, al aprobarse la reforma de la ley en febrero de 1942, uno de los supuestos de sobreseimiento atendía directamente a la capacidad económica del encartado (7). Finalmente, estas penas económicas no dependían únicamente de la «gravedad de los hechos apreciados». Debía tenerse en cuenta «la posición económica y social del responsable y las cargas familiares que legalmente esté obligado a sostener» (8).

Más allá del contenido explícito de la ley, un procesamiento por responsabilidades políticas implicaba la marginación -y miseria- económica del encartado, pero también de sus familiares -fundamentalmente cónyuge e hijos si los había-. El embargo cautelar, el pago de la multa... en definitiva las consecuencias económicas, afectaban de manera colectiva a todo el núcleo familiar -incluso más allá-. En no pocos casos los documentos contenidos en los expedientes revelan la insolvencia o la pobreza extrema de encausados y encausadas. La posibilidad de pagar una sanción por parte de estas personas es inconcebible. Las casuísticas más dramáticas que reflejan son aquellos en los que ambos cónyuges han sido represaliados; o aquellos en los que mujeres solas con hijos al cargo (viudas; esposas de presos, huidos o «desaparecidos») deben enfrentar como «cabeza de familia» el espiral de miseria y violencia de los años cuarenta.

La incapacidad para pagar una sanción no desvirtúa la capacidad represiva de la ley. El grueso de las actuaciones se extiende en el primer lustro de una dura década de posguerra marcada por la miseria y la violencia: son los años del hambre, las penurias extremas, los juicios, las depuraciones o las cárceles abarrotadas. Es en este contexto en el que se sumaba otro procedimiento más. Desde el momento en que un expediente se abría este cumplía ya una finalidad intimidatoria. A ello se sumaban las distintas diligencias practicadas por los

Zaragoza: http://www. unizar. es/ice/uez/wp-content/uploads/2008/10/1939-ley-de-responsabilidades-polaticas. pdf

(5) Definiciones extraídas del diccionario online de la Real Academia Española de la Lengua.

(6) Para las sanciones y su aplicación véase el capítulo III del título I de la ley. En el caso de la transmisión, el articulado prevé la extensión de la responsabilidad más allá del individuo en lo que se refiere a las sanciones económicas. En caso de fallecimiento o ausencia será sobre los herederos sobre quienes recaerá el proceso.

(7) La ley de 19 de febrero de 1942 sobre reforma de la de Responsabilidad Política fue publicada en el BOE el 7 de marzo. El artículo $8 .^{\circ}$ preveía el «sobreseimiento automático de los expedientes cuando la valoración de bienes practicada suponga bien la insolvencia del inculpado [...] o cuando el conjunto de sus bienes fuese de un valor inferior a 25.000 pesetas».

(8) Artículo 13, LRP. 
Jueces Instructores. Ir a declarar y a presentar la relación jurada de bienes si no se hallaban encarcelados podía implicar la pérdida de un día de jornal, además de despertar el temor de quienes debían adentrarse en dependencias judiciales. Por su parte, las autoridades rondaron en muchas ocasiones el vecindario de los encausados para realizar el preceptivo informe con el consiguiente efecto coactivo.

Los plazos establecidos como improrrogables no se cumplieron. Los procesamientos se alargaron durante años y con ellos la angustia de verse encausado en otro procedimiento que planeaba sobre sus escasos o nulos medios de vida. En este sentido, la Ley de Responsabilidades Políticas fue «un eficaç instrument a l'hora d'aplicar un escarment social, neutralitzador de futures veus dissidents i generador, alhora, de passivitats submises». Esto es, funcionó también como resorte de control, humillación, marginación y coacción. Otro mecanismo represivo más que pudo generar sentimientos de resignación, hostilidad, temor, etc. Efectos «no comptables» (9) difíciles de valorar y baremar, pero que no por ello deben ser olvidados o subestimados.

Si continuamos centrando nuestra atención en el contenido del preámbulo de la ley encontramos, entre otras tantas, la siguiente aseveración: «la magnitud, intencional y las consecuencias materiales de los agravios inferidos a España son tales, que impiden que el castigo y la reparación alcancen unas dimensiones proporcionadas». Tal declaración persiste en el ejercicio ampliamente practicado por la dictadura de legitimarse a través de una reinterpretación -cínica- del pasado más reciente. La lectura franquista del golpe de Estado y la Guerra Civil demoniza el pasado republicano a la par que transforma una sublevación contra un gobierno legal y legítimo en un necesario e ineludible «Movimiento Nacional». Esta tergiversación de los roles desempeñados y los hechos acontecidos sirvió como base ideológica para legitimar también la represión contra la «anti-España», dando cobertura a los instrumentos legales que la legitimarían también jurídicamente.

El ejemplo más paradigmático de esta legitimación por la vía judicial es esa práctica de la «justicia al revés» de los Consejos de Guerra. La Ley de Responsabilidades Políticas continúa por esta senda justificándose explícitamente a través del preámbulo o del castigo retroactivo de supuestos delitos políticos que en el momento de producirse no solo eran legales sino que formaban parte de la vida política -algunos de estos comportamientos políticos habían sorteado hasta el momento la acción represiva-. En palabras de Manuel Álvaro: «La Ley es en sí un instrumento de legitimación ideológica del Estado franquista, en la medida en que los "delitos" que reprime encierran la clave de la "destrucción

(9) Traducciones propias: «un eficaz instrumento de control a la hora de aplicar un escarmiento social, neutralizador de futuras voces disidentes y generado, al mismo tiempo, de pasividades sumisas». Y: «no contables». CORRETGÉ, FARRÉ, Mir y SAGUÉS (1997): 355 y 360. 
material y espiritual de la Patria" y, por tanto, la justificación de la sublevación militar y la "Cruzada"» (10).

El artículo $4 .^{\circ}$ recoge las diecisiete causas por las que podía incurrirse en responsabilidades políticas. La primera de ellas era «haber sido o ser condenado por la jurisdicción militar por alguno de los delitos de rebelión». Este supuesto implica la posibilidad de que un inculpado fuese juzgado y condenado dos veces por un mismo hecho. Una duplicidad judicial que incumple sistemáticamente el principio jurídico non bis in idem. El despropósito es mucho mayor si se tiene en cuenta el gran número de expedientes cuyo motivo de apertura -las sentencias provenientes de la jurisdicción castrense- y causa de responsabilidad -haber sido ya condenado- es este primer apartado a) del artículo 4. ${ }^{\circ}$ (11).

Las otras dieciséis causas contemplan un abanico tan amplio y difuso de supuestos que casi cualquiera podía verse procesado, más si tenemos en cuenta la imprecisión del vocabulario empleado y el afán represivo mostrado por los sublevados. Dirigentes de partidos, agrupaciones y asociaciones; personas con misiones «de confianza» por nombramiento del Frente Popular; altos cargos, candidatos, apoderados, interventores o afiliados (en teoría no los afiliados a sindicatos) en las elecciones de 1936. Todos ellos se encontraban bajo el aura de la culpabilidad. A estos se sumaban otros tantos que habían permanecido en el extranjero durante la guerra, se habían «opuesto de manera activa al Movimiento Nacional», habían «realizado cualesquiera otros actos encaminados a fomentar con eficacia la situación anárquica en que se encontraba España...», o habían «excitado o inducido» por cualquier medio (también de palabra, véanse las posibilidades de denuncias en estos casos) los desdibujados hechos y cargos recogidos en otros supuestos.

Indeterminación, ambigüedad y vaguedad son las características que predominan en la relación de las culpas a liquidar. Permitía que un gran número de personas cupiesen en el centro de la diana y dejaba mucho espacio a la valoración subjetiva. Este amplio espacio de interpretación no era casual y dejaba a la dictadura la capacidad de regular la intensidad de la represión atendiendo a criterios políticos (12). Por su parte, se dejaba mucho margen de maniobra a unos Tribunales que dependían en última instancia de Vicepresidencia de Gobierno y en los cuales el protagonismo y la preponderancia de los militares es indiscutible (13).

La culpabilidad se agravaba siguiendo un criterio tan difícilmente mesurable como la supuesta relevancia de la persona en su entorno -para determinadas

(10) Álvaro (2006): 97-98. Para la legitimación ideológica y jurídica de la represión véanse también las páginas 47-63.

(11) BARRAGÁN (2009): 188.

(12) Así lo reconoce explícitamente la Ponencia. Álvaro (2006): 102.

(13) Ello implicaba que los militares juzgarían comportamientos estrictamente políticos. Sobre el protagonismo de los militares en la jurisdicción de Responsabilidades Políticas véase ÁLVARO (1990): 141-162. 
figuras en los pueblos esto podía implicar una condena- (14). Solo estaban exentos los menores de catorce años y aquellos que hubiesen prestado «servicios extraordinarios»: los combatientes voluntarios desde «los primeros momentos del Movimiento», los heridos graves, los condecorados con determinados títulos, etc. Al final, solo estaban libres de toda culpa aquellos que pudiesen demostrar una adhesión sin fisuras o los niños. Las circunstancias atenuantes continúan en la misma línea: atendiendo a la edad -ser menor de dieciocho años mitigaría la culpabilidad-; y a los servicios prestados -adeptos cuyas prestaciones no hubiesen sido tan reseñables-.

Los hechos susceptibles de ser condenados según la Ley de Responsabilidades Políticas suponen «un giro significativo en la consideración del delito, al hacerse explícito por primera vez el concepto de "responsabilidad política"» (15). El artículo 4. ${ }^{\circ}$ es en su conjunto un inventario de «pecados democráticos» (16) que recoge actitudes y actuaciones legales, legítimas y normalizadas en el momento en que se produjeron. Es más: actitudes y actuaciones en favor de un Estado republicano legal y legítimo contra el que se produce un golpe de Estado militar. En este sentido la ley excede su objetivo represivo para convertirse en un potente instrumento de legitimación ideológica. Declarando ilegal lo anterior se legitima el origen y ejercicio del poder de la dictadura (17).

La ley vulnera así otro principio jurídico: nullus crime sine lege. Se castigan delitos que no eran considerados como tal en el momento en que se produjeron. Lo hace además con carácter retroactivo, otra de las aberraciones jurídicas más reseñadas por juristas e historiadores. En su artículo $1 .^{\circ}$ declara la responsabilidad política de todos los que desde octubre de 1934 «contribuyeron a crear o agravar la subversión de todo orden». También a los que desde julio de 1936 «se hayan opuesto o se opongan al Movimiento Nacional con actos concretos o con pasividad grave». La retroactividad también es explícita en los supuestos de responsabilidad. La necesaria legitimación de un golpe de Estado pasaba por no reconocer la legalidad del Estado republicano. En consecuencia, se debía estigmatizar y castigar a sus protagonistas, ¿Cómo hacerlo a posteriori sin condenar con retroactividad?

La transmisión de la sanción; la apertura y continuación de expedientes contra personas fallecidas; la ilegalidad del sistema punitivo (18); la conculcación

(14) Según el artículo 7 de la LRP: «se tendrá en cuenta para agravar la responsabilidad del inculpado su consideración social, cultural, administrativa o política cuando por ella pueda ser estimado como elemento director o prestigioso en la vida nacional, provincial o local, dentro de su respectiva actividad».

(15) Cenarro (2014): 30.

(16) Álvaro (2012): 60-106.

(17) Álvaro (2006): 97 y ss.

(18) García I Fontanet (2000): 143. El autor se refiere especialmente a la incautación total de bienes, la pérdida de la nacionalidad española y el carácter imprescriptible de las sanciones económicas. 
de principios jurídicos; el carácter retroactivo. Estas y otras perversiones han llevado a los investigadores a calificar la Ley de Responsabilidades Políticas en términos de «aberración jurídica» (19) o «monstruosidad jurídica» (20). De inicio, la ley creaba ya una jurisdicción especial con unos organismos específicos que debían aplicarla con la ausencia de garantías que ello conllevaba. Se establecieron dieciocho Tribunales Regionales, de los que dependían Juzgados Instructores Provinciales y Juzgados Civiles Especiales. En la cúspide se situaba el Tribunal Nacional dependiente de Vicepresidencia del Gobierno.

La actuación de los distintos organismos competentes agudizó el carácter represivo y arbitrario de la ley en su afán depurativo. La tónica ante la ambigüedad fue el perjuicio para los procesados. Asimismo, como evidenciaban los mismos encausados, la tendencia en la instrucción y fallo de los expedientes fue la conculcación del principio in dubio pro reo y la negación de la presunción de inocencia: «un procesado era culpable hasta que se demostrase lo contrario» (21). La incoación, instrucción y fallo de los expedientes seguían el ritmo de un baile de pasos cortos. Los plazos para el cumplimiento de las distintas diligencias previstas por la ley eran exiguos, lo cual dificultaba la capacidad de defensa de los encausados -sumado a su desconocimiento de la procedencia de las acusaciones, entre otros tantos factores-.

Los Tribunales Regionales ordenaban la formación de expedientes por sentencias llegadas de la jurisdicción de guerra, por propia iniciativa o por denuncias -de particulares o de autoridades-. La información con la orden de incoación se remitía al Juzgado Instructor. Los jueces debían instruir los expedientes y elevarlos de nuevo junto a un resumen metódico en el plazo de un mes. En ese tiempo debían publicar el preceptivo anuncio de incoación en los Boletines Oficiales y recabar información sobre los inculpados. Para ello, citaba al procesado - quien tenía cinco días para comparecer-y solicitaba informes a las autoridades locales de su lugar de residencia -disponían también de cinco días para remitirlos-. Si se personaba el procesado -su incomparecencia no detenía el procedimiento-, se le hacía lectura de los cargos y se le daban -más- plazos para aportar pruebas en su defensa si lo deseaba -cinco días- y una relación valorada de sus bienes -ochos días-. A este respecto, la ley contempla distintas circunstancias -fallecimiento, ausencia, ocultación de bienes-.

Elevados los expedientes al Tribunal Regional se iniciaba otro baile de días que variaba en función de las resoluciones de los distintos pasos. A modo orientativo: cinco días de instrucción del ponente, un día para dictar acuerdo, tres días de publicación en secretaria de los autos, dos días para el escrito de defensa, cinco

(19) CARRILlo (2007): 77

(20) CANO (1985): 93. En los mismos términos analiza la ley García i Fontanet en el capítulo citado.

(21) Murillo (2014a): 231. 
días para dictar sentencia (22). En la práctica los días se convertirán en semanas o meses y los meses se convertirán en años. Correspondía a los Tribunales Regionales vigilar la «rápida tramitación de los expedientes» solicitando estadillos y «apercibiéndoles por las faltas de celo y actividad que observen». En Valencia, esta valiosa documentación no se ha conservado o no es consultable (23).

La burocratización es brutal, practicándose las diligencias de forma rutinaria y sistemática. El alargamiento de los improrrogables plazos no conllevó necesariamente mejores posibilidades de defensa. Las escasas posibilidades -el escrito de defensa o el recurso de alzada como última instancia- fueron utilizadas por los procesados aunque dado el afán represivo de la ley y sus organismos podría cuestionarse hasta qué punto se tuvieron en cuenta (24). La misma ley disuadía: en caso de que el Tribunal Nacional considerara temerario el recurso de alzada podría imponer una multa de hasta el 10\% del importe de la sanción económica (25).

Seguramente no es aventurado conjeturar el desequilibrio en la valoración de las informaciones recibidas por Juzgados Instructores y Tribunales Regionales. Debemos tener en cuenta el afán depurador, la escasa labor probatoria de las jurisdicciones represivas de la dictadura franquista y la opuesta consideración entre «gentes de orden» y vencidos. En este sentido, es probable que entre los testimonios recogidos los jueces dieran un mayor valor a las informaciones acusatorias y provenientes de las autoridades o vecinos «de reconocida solvencia moral». Inculpaciones que, más que en datos objetivos, muchas veces se basaban en juicios morales, el rumor público, las vivencias personales, el afán revanchista o arribista (26).

¿Cuándo la Ley de Responsabilidades Políticas se convirtió en un problema? ¿Cuándo se iniciaron los problemas en un procedimiento que parecía atado

(22) Para el fallo del expediente véase el capítulo IV de la LRP.

(23) En el Archivo del Reino de Valencia (en adelante ARV) se conservan algunos -pocoslegajos de burocracia interna. No obstante, en su totalidad se refieren a la segunda etapa (a partir de la reforma de 1942). En este mismo fondo documental se encuentra el grueso de expedientes consultables en la provincia de Valencia. Algunos contienen información relativa a los cambios de titularidad en los Juzgados Instructores. Conforman según nuestros cálculos una tercera o cuarta parte del total. Sabemos que se han conservado otros que se encuentran dispersos en diferentes instituciones que no permiten el acceso o en archivos de carácter municipal, las más de las veces sin catalogar o sujetos a restricciones.

(24) Sobre la utilización del contenido de la propia ley para escamotear las sentencias y las multas véase MURILLO (2014b): 203-226.

(25) Dado el carácter político de las sentencias y el contexto en el que se producirán, las posibilidades de que un recurso se resolviera favorablemente eran remotas, por lo que la amenaza de un incremento de la sanción económica funcionó como un eficaz mecanismo disuasorio. ÁlVARO (2006): 118.

(26) Al respecto véanse los trabajos de Nacho Moreno y Estefanía Langarita para el caso de Aragón. Sobre las denuncias e informes de las autoridades locales Moreno (2014): 119-142. Para las colaboraciones ciudadanas, formas y tipologías de motivación LANGARITA (2014): 145-173. 
y bien atado? ¿Cuándo se inició el desequilibrio entre resoluciones y pendientes? ¿Cuándo los expedientes sin resolver, a media instrucción o sin incoar se convirtieron en un cúmulo, en una montaña? Y, ¿por qué? Según Manuel Álvaro en octubre de 1941 el Gobierno disponía ya de «datos incuestionables» que apuntaban que la Ley de Responsabilidades Políticas «se había convertido en un problema de dimensiones importantes» (27). El cúmulo ya se había convertido en montaña y no había visos de que la situación mejorase. El 19 de febrero de 1942 se promulgaría la ley «sobre reforma de la de Responsabilidades Políticas». Entre otros, se suprimió la jurisdicción especial y las competencias pasaron a la justicia ordinaria -la ley no perdió su carácter excepcional-; se contemplaron supuestos de sobreseimiento automático; y se modificó parcialmente la parte procesal (28).

El afán represivo de la ley y de los organismos encargados de su aplicación; la interpretación -y en ocasiones vulneración- de las partes más ambiguas del texto legislativo encaminadas siempre hacia la mayor depuración posible; el consiguiente alud de expedientes; la insuficiencia de recursos y estructura para llevar a cabo una labor depuradora tan titánica; un procedimiento que en la práctica resultó no ser ni rápido ni sencillo; el temprano desequilibrio entre pendientes y resueltos. Interrelacionados entre sí, son posiblemente estos los factores que mejor explican el rápido colapso de la jurisdicción de Responsabilidades Políticas. Un desmesurado fin que justificó «un medio jurídicamente poco escrupuloso» (29). Un desmesurado fin que rebasó las posibilidades del medio.

La provincia de Valencia no fue una excepción. La tardía ocupación por parte de las tropas franquistas implicó la ausencia previa de una Comisión Provincial de Incautación de Bienes. La colosal tarea debía empezarse de cero. En unos meses tuvo que crearse, como en otras provincias, un segundo Juzgado Instructor. No fue suficiente. Ni siquiera el primero de los juzgados comenzó con buen pie. Los expedientes pendientes de incoar o de distintas diligencias se amontonaron en ambos juzgados.

\section{LOS INICIOS DE LA MONTAÑA. LA FORMACIÓN DEL TRIBUNAL REGIONAL DE VALENCIA}

El 9 de febrero de 1939 todavía quedaba más de un mes y medio para la entrada de las tropas franquistas en la ciudad de Valencia y el archiconocido último parte de guerra. No fue hasta el 29 de marzo cuando los periódicos anunciaron la inminente llegada de los sublevados a la ciudad. Solo un día después

(27) Álvaro (2006): 158-159.

(28) BOE de 7 de marzo.

(29) Állvaro (2006): 102. 
tuvo lugar el desfile de los militares (30). Ese mismo día 30 de marzo de 1939 el general jefe del Ejército de Levante declaraba mediante bando, como venía siendo habitual tras la ocupación, el estado de guerra. Una paradoja o un gesto inequívoco de que lo que llegaba no era una paz sin apellidos. En virtud de este bando «queda[ba]n sometidos a la jurisdicción Castrense todos los delitos cometidos a partir del 18 de julio de 1936, sea cualquiera su naturaleza» (31). Los Consejos de Guerra Permanentes se encargarían de instruir y fallar las actuaciones ajustándose al modelo del Procedimiento Sumarísimo de Urgencia (32). El engranaje represivo judicial empezaba a funcionar en Valencia.

Durante las siguientes semanas el Boletín Oficial de la Provincia (en adelante BOPV) llenó sus páginas a rebosar de leyes represivas. Entre ellas, la Ley de Responsabilidades Políticas se publicaría en catorce entregas entre los días 8 y 24 de abril. Implicaba simbólicamente el inicio de la represión económica judicial en la provincia. La siguiente publicación relativa a la misma fueron las normas sobre la administración de las sanciones económicas, insinuante de la finalidad y los intereses del «Nuevo Estado». Para los «territorios de reciente liberación» se dieron instrucciones sobre cómo proceder «hasta que se constituyan los organismos establecidos enla Ley deResponsabilidades Políticas» (33). Generales jefes del Ejército -o de región militar- y gobernadores militares podrían ordenar la instrucción de un breve atestado que incluyese los datos básicos del posible responsable político.

De esta forma, antes de la constitución de tribunales y juzgados podía iniciarse ya la ingente tarea y los posibles embargos. Planas de Tovar, gobernador civil de Valencia, se sumergió presto a la tarea encomendada. Mediante circular, ordenaba a las Comisiones Gestoras de los ayuntamientos el inventariado, tasación e incautación de los «bienes de todas clases, créditos y efectos» que pudieran pertenecer a partidos, sindicatos o asociaciones prohibidas (34). A ese mismo Gobierno Civil se debía dar acuse de recibo y del cumplimiento de lo ordenado. Todas estas actuaciones debían ser remitidas con posterioridad al Tribunal Regional de Valencia.

El 2 de junio de 1939, por orden de la Vicepresidencia del Gobierno, se nombró al personal que conformaría los organismos competentes en materia de responsabilidades políticas en la provincia. Esto es, al personal del Tribunal

(30) GABARDA (2007) [1993]: 43-46.

(31) BOPV de 31 de marzo. El BOPV ha sido consultado en el Archivo de la Diputación de Valencia (en adelante ADV) y en la Hemeroteca Municipal de Valencia (en adelante HMV).

(32) Sobre la justicia militar y los Procedimientos Sumarísimos de Urgencia puede verse por ejemplo GIL (2004). Una descripción muy clarividente del funcionamiento de los Consejos de Guerra en MORENO (1999): 316-322.

(33) Orden de Vicepresidencia de 6 de mayo de 1939. BOPV de 16 de mayo. Gobierno Civil volvería a reproducir la orden en BOPV de 6 de junio.

(34) Circular de Gobierno Civil de 17 de mayo de 1939. BOPV de 18 de mayo. 
Regional de Valencia -con jurisdicción también en Castellón y Alicante (35)-, del Juzgado Civil Especial y del Juzgado Instructor Provincial. De los trece cargos nombrados, entre titulares y suplentes, cinco de ellos eran miembros del estamento militar (36). Además, los puestos que desempeñarían eran claves en la aplicación de la ley: la presidencia del Tribunal Regional y el «equipo» del Juzgado Instructor - juez y secretario-. Esto es, el vértice del órgano encargado de fallar los expedientes y a quien correspondía su instrucción.

La primera noticia sobre los inicios de la jurisdicción en Valencia aparece publicada en el periódico Levante el 8 de julio de 1939. El diario informaba que los organismos provinciales previstos por la ley se habían constituido y habían comenzado su actuación (37). Apenas unos días después el recién estrenado Tribunal iniciaba la centralización de la represión económica. Los primeros acuerdos de incoación por parte del Tribunal de los que tenemos noticia a través de las listas publicadas en el BOPV se remontan a mediados del mismo mes de julio. Por otra parte, ordenaba a organismos, entidades y particulares que se le comunicara en ocho días los bienes de todo tipo que se hallaban en su poder. Parece que se era consciente que estos haberes podían proceder de incautaciones y requisas más o menos oficiales, pero también de ocupaciones particulares (38).

Las denuncias o comunicaciones de las autoridades debían llegar en última instancia al Tribunal Regional. Si se entendía de la información recabada (39) o de las denuncias recibidas que había indicios de responsabilidad política se ordenaba la incoación de expediente; en caso contrario, se archivaba. A la ambigüedad y el afán represivo de la misma ley se unió la sed de purga de las autoridades locales, de algunos vecinos y del mismo Tribunal Regional. Algunas de las listas y denuncias que se remitieron contenían informaciones sesgadas y/o inexactas que no permitían la normal instrucción. Pese a ello, se cursaron y, pese a ello, se ordenó la formación del correspondiente expediente. No deja de resultar cuanto menos llamativo y no se encuentra otra motivación que un irracional afán depurador. Veamos algunos casos.

Tras la entrada en vigor de la reforma de 1942, el juez decano de la capital debía repartir los expedientes procedentes de los extintos Juzgados Instructores

(35) Sobre estas provincias contamos por ejemplo con los trabajos de Fernando Peña para Castellón y de Glicerio Sánchez para el partido judicial de Monóvar (Alicante). Véase PEÑA (2010) y SÁNCHEZ (1984).

(36) Orden de Vicepresidencia de 2 de junio de 1939. BOPV de 16 de junio.

(37) Diario Levante, 8 de julio de 1939, p. 2. HMV

(38) Tribunal Regional de Responsabilidades Políticas de Valencia, 12 de julio de 1939. BOPV de 13 de julio.

(39) El mismo Tribunal solicitó información sobre posibles responsables políticos. Por ejemplo, en octubre de 1939 solicitaba al Ayuntamiento de Valencia toda la información posible sobre el personal del ayuntamiento, los intelectuales y aquellos que pertenecían a la masonería. Aguado y Verdugo (2011): 65-66. 
entre los de Primera Instancia de la capital. Al número 6 de Valencia llega en el verano de 1942 la orden de proceder contra los hermanos Ángeles y la mujer de Pérez. No hay noticias de que se hubiera iniciado la instrucción previamente, si bien debía haberse ordenado dado que provenía del Juzgado Instructor Provincial número 2 y no del Tribunal Regional -¿cuántos se acumularían así?-. Aunque constan como «no empadronados» supuestamente eran vecinos del Grao (Valencia). Desconocemos el vecino o autoridad denunciante.

Pese a los escuetos datos -si es que pueden considerarse como tal-, el juez número 6 ordena el anuncio correspondiente en los Boletines Oficiales y la petición de informes a las autoridades locales. Tras tres meses infructuosos, eleva las diligencias practicadas a la Audiencia Provincial dando por infundada la denuncia. Esta devolverá el expediente y ordenará que se recabe información a través del juez decano de la capital. En octubre de 1943, el juez número 6 volverá a remitir el expediente a la Audiencia indicando que no hay más datos que los que se aportaron desde el primer momento. Este expediente sin inculpado claro no será sobreseído hasta octubre de 1945, ya por la Comisión Liquidadora de Responsabilidades Políticas (40).

En las mismas circunstancias, «por reparto», llegará al número 3 de Valencia otro expediente pendiente de incoación. La supuesta responsable era Azucena Pérez, contra la que existía orden de proceder en virtud de una relación remitida en diciembre de 1939 por la Comandancia de la Guardia Civil del Grao. Azucena Pérez era una «posible maestra», hija de un tal «Pedro Pérez» y se ignoraba su paradero. Era también la «fanática sobrina de José Pons, peligrosa, espía contra elementos de derecha». A la postre, anarquista. Las autoridades locales nunca pudieron dar ningún dato sobre ella. El expediente será sobreseído por la Audiencia (41).

Si la localización de los supuestos responsables ya supuso habitualmente un problema para los jueces, la ausencia, imprecisión o errores de datos imposibilitó o ralentizó la ya de por sí lenta instrucción de los expedientes. Menos escandalosos que los anteriores, pero igualmente llamativos, son otras casuísticas en las que se varían los apellidos e incluso el sexo de los procesados. El Tribunal Regional -después la Audiencia- dio luz verde a estas denuncias sin ninguna labor de contraste, incluso a aquellas más incoherentes que carecían hasta de un sujeto claro. El afán de revancha y la dejación dificultaron o cargaron de trabajo estéril a unos ya de por sí saturados Juzgados Instructores con el consiguiente desvío de esfuerzo y pérdida de tiempo.

Por su parte, las autoridades judiciales militares debían enviar al Tribunal correspondiente testimonio de las «sentencias firmes condenatorias» (42). A su

(40) Expediente de Responsabilidades Políticas (en adelante ERP) contra los hermanos Ángeles y la mujer de Pérez, fondo Carlet, caja 4255/2, ARV.

(41) ERP contra Azucena Pérez, fondo Valencia, caja 4089/37, ARV.

(42) Artículo 37, LRP. 
vez estos debían «remitir a los Jueces Instructores Provinciales los testimonios que reciban de la Jurisdicción de Guerra en los casos a que alude el epígrafe a) del artículo cuarto» (43). Esto es, cursar aquellos cuyo fallo era la condena por delito de rebelión en alguna de sus formas. Procedentes del Juzgado Militar número 8 llegaban al Tribunal de Valencia las copias de los autos-resumen de los Consejos de Guerra. En estos casos, esta documentación ocupa las primeras páginas del expediente. Si el Consejo de Guerra era colectivo podía derivarse un procedimiento por responsabilidades políticas también colectivo o, por el contrario, individual de cada uno de los procesados.

Sin embargo, como señala Fernando Peña para el caso de Castellón: «la voluntad represiva fue tan intensa que se desbordaron los límites que la misma Ley de Responsabilidades Políticas establecía». Y es que «en la práctica se procesó por responsabilidades políticas a todas las personas que pasaron por un consejo de guerra» (44). Tribunales militares y Tribunales Regionales de Responsabilidades Políticas contravinieron de entrada la propia ley. Los primeros enviaron todas las sentencias independientemente del fallo. Los segundos ordenaron la formación de expedientes. No serán menos los Juzgados Instructores quienes iniciaran diligencia contra todos los que figuran en el auto-resumen.

Ello conllevaba una vulneración aún más flagrante de los principios non bis in idem e in dubio pro reo. Los sospechosos fueron juzgados dos veces por el mismo delito, procediendo la segunda vez de un juzgado - militar- que los había absuelto. En este sentido, la jurisdicción de Responsabilidades Políticas no solo complementó y completó en el plano económico las condenas de los Consejos de Guerra. También superó a la represión de la jurisdicción militar ampliando la lista de candidatos. La traspasó la larga y ambigua lista de supuestos para incurrir en responsabilidad política. La acabó de rebasar la actuación de los organismos implicados en la aplicación de la ley.

Su absolución no los libró de los perjuicios de la cárcel y la represión económica. Por ejemplo, Bárbara Lluesma fue absuelta por la jurisdicción militar en agosto de 1939. Antes de la vista oral había estado tres meses en prisión preventiva. Y otro mes más después hasta que se tramitó y tuvo efecto el resultado de la misma (45). Había sido absuelta, pero el secretario del Juzgado Militar 8 remitió la copia de la sentencia al Tribunal. Después, el Tribunal la remitió junto con la orden de proceder en diciembre de 1939 al Juzgado número 1. El inicio de facto de la instrucción no se produjo hasta un año después, en noviembre de 1940. El expediente pasó a la jurisdicción ordinaria sin haber localizado el paradero o domicilio de la encausada (46).

(43) Artículo 26, LRP.

(44) PEÑA (2010): 119-121.

(45) Expediente penitenciario (en adelante EP) de Bárbara Lluesma, Picassent II, mujeres, caja $210 / 3$, ARV.

(46) ERP contra Bárbara Lluesma, fondo Valencia, caja 4079/35, ARV. 
En definitiva, el afán depurador de la misma ley primero y el de las autoridades, denunciantes y el propio Tribunal Regional después, generaron una montaña de órdenes de proceder contra posibles responsables. ¿Se acumularon estas órdenes en los Juzgados Instructores pendientes de ejecutar? ¿Se amontonaron expedientes en pleno proceso de instrucción? Para la provincia de Valencia no toda la documentación generada por la jurisdicción de Responsabilidades Políticas se ha conservado o es consultable en el Archivo del Reino. Sin embargo, algunas pistas podrían apuntar a una respuesta afirmativa de las dos cuestiones.

La primera lista de anuncios de incoación en el BOPV -diligencia que el juez instructor ordenaba inmediatamente al incoar expediente- no se publicó hasta pasados dos meses. Por su parte, en aquellos expedientes que se conserva la orden de proceder remitida por el Tribunal Regional se observa el desfase entre la remisión y el inicio de la instrucción. Finalmente, con la reforma de 1942 -y la consiguiente extinción de los Juzgados Instructores de Responsabilidades Políticas- la ya presumible montaña de trabajo pasó a la justicia ordinaria. A los Juzgados de Primera Instancia -encargados ahora de la instrucciónllegaron los expedientes todavía en tramitación; pero también llegaron relacionados de posibles responsables sobre los que había una orden de proceder nunca ejecutada.

\section{LA MONTAÑA ACUMULADA. LA ACTUACIÓN DE LOS JUZGADOS INSTRUCTORES}

Una vez recibida la orden de incoación, correspondía a los Juzgados Instructores continuar la tramitación de los expedientes. En su primera providencia ordenaban la publicación en los Boletines Oficiales del preceptivo anuncio de incoación (47). La fecha de esta primera disposición coincide o apenas se distancia en pocos días de la fecha de remisión al BOPV. De ahí la importancia de esta documentación: es clave para aproximarnos al momento en el que efectivamente se inician las actuaciones de la instrucción contra los encausados. Nos asegura que ya se había iniciado de facto esta etapa del procedimiento -cuestión aparte es el tiempo que tarda en finalizarse la misma-. En otras palabras, el anuncio de incoación implica que se ha puesto en marcha la maquinaria del juzgado. Nos ayuda a diferenciar dos etapas en esa montaña acumulada en los juzgados provinciales. La primera: recibida la orden del Tribunal Regional

(47) Según el artículo 46 de la LRP los anuncios de incoación debían contener los siguientes datos: «nombre, apellidos, profesión u oficio, estado, vecindad y domicilio de los inculpados; Tribunal Regional de Responsabilidades Políticas que haya acordado la incoación del expediente, con expresión de la fecha del acuerdo, y Juzgado de Instrucción Provincial que lo esté tramitando». Igualmente se hacía saber que el fallecimiento, ausencia o incomparecencia no detenía el procedimiento; y que debían prestar declaración todos aquellos que pudiesen informar de la conducta o los bienes de los encausados. 
pero pendiente de ejecutarse. La segunda: en fase de instrucción. El bloqueo se produjo en ambas.

Paralelamente, el juez debía citar al inculpado o inculpada y recabar información sobre sus antecedentes políticos y su situación socioeconómica. En el primero de los casos debía localizarse su paradero o el establecimiento penal en el que estuviera cumpliendo condena. Entonces, se la citaba a declarar, se le leían las prevenciones y se le solicitaba la presentación de una declaración jurada de bienes (48). Por su parte, el juez solicitaba informes a las autoridades locales de la población donde el encartado residía y/o de la que era natural (49). Con todos los datos recabados el juzgado debía remitir el expediente al Tribunal Regional junto con un resumen metódico que contuviese «todas las pruebas practicadas», así como su «parecer acerca de la responsabilidad o irresponsabilidad del inculpado» (50).

En su capítulo tercero la ley estipula cuáles eran los pasos a seguir por los Juzgados Instructores. A primera vista el procedimiento parecía sencillo, rápido y sistemático. Puede intuirse que, ante un previsible cúmulo, el nivel de burocratización rutinaria con todas sus consecuencias sobre el encartado sería brutal. Pero eso fue sobre papel. En Valencia, a la montaña de expedientes pendientes de iniciarse la instrucción se sumó la montaña de expedientes pendientes de cumplir alguna de las diligencias marcadas por la ley. Por un lado, los juzgados se colapsaron acumulando casos pendientes. Por otro, el procedimiento en su fase de instrucción resultó imposible de cumplir en los plazos estipulados. ¿Cuántos se acumularon pendientes de iniciarse? ¿Cuántos se estancaron en la etapa de instrucción propiamente dicha?

Las primeras informaciones de su constitución en Valencia coinciden con las del Tribunal Regional. La orden de Vicepresidencia de junio de 1939 nombra al personal que conformaría el primer juzgado. Como juez, se designó a

(48) Según el artículo 49 de la LRP tras la declaración el juez debía hacerle al encartado cinco prevenciones. La primera y la segunda aludían a la prohibición de ausentarse de su lugar de residencia sin permiso del juez -en caso de incumplimiento sería detenido y procesado por desobediencia grave-. La tercera, la cuarta y la quinta se referían a los bienes del encausado. Debía presentar una relación jurada de bienes que incluyese los de su cónyuge y otros datos (deudas, hijos...). No presentarla se castigaría como delito de desobediencia grave. Ocultar bienes o simular deudas como delito de falsedad en documentos públicos. Finalmente, se le apercibía que no podía realizar desde ese momento actos de disposición de bienes -en caso contrario podría ser procesado por alzamiento de bienes o desobediencia grave. Si se hallaban en la cárcel solo se les hacían las prevenciones relativas a sus bienes $\left(3 .^{\mathrm{a}}, 4 .^{\mathrm{a}}\right.$ y 5 . $\left.^{\mathrm{a}}\right)$ por conducto del director de la misma.

(49) Según el artículo 48 de la LRP estas autoridades eran el «Alcalde, Jefe local de Falange Española Tradicionalista y de las J. O. N. S. , Cura Párroco y Comandante del Puesto de la Guardia [...]». Si habían residido o residían en la capital de la provincia se añadía la Jefatura de Policía. En un plazo de cinco días estos debían informar sobre los antecedentes político-sociales y los bienes del encartado. Si ya había sido condenado por la jurisdicción militar el juez únicamente solicitaba información de sus condiciones socio-económicas (artículo 53).

(50) Artículo 29 d), LRP. 
Enrique de Iturriaga. Como secretario y secretario suplente, a Adolfo González y Ángel Cristóbal respectivamente. Todos ellos pertenecían al estamento mili$\operatorname{tar}(51)$. Se instaló en un principio en el mismo domicilio que el Tribunal Regional.

En cuanto a su funcionamiento, es imposible precisar la fecha exacta en que el juzgado comenzó su labor. Pueden realizarse aproximaciones si bien estas son cuanto menos problemáticas. Carecemos de datos que nos indiquen que en julio y agosto el juzgado desarrolló actividad. Los primeros apuntes en ese sentido se refieren a los primeros días de septiembre. Adolfo González jura su cargo ante Enrique de Iturriaga el 5 de septiembre de 1939 (52). A tenor de la documentación, el secretario fue en la práctica una figura clave en la labor de instrucción de los expedientes. Por ello, es probable que las tareas del Juzgado Instructor no se iniciasen mucho antes de esta fecha -si lo hicieron- o bien el secretario juró con posterioridad a su incorporación. Asimismo, el juez inicia las actuaciones de varios expedientes en los primeros diez días del mes (53).

Las primeras listas de encartados fueron publicadas en el BOPV los días 20 y 21 de septiembre de 1939 -ambas remitidas el 18 de septiembre-. Las fechas de acuerdo del Tribunal se remontan a como mínimo un mes antes de la remisión. Los tiempos no difieren de los de otras provincias. En Madrid los primeros expedientes se abren en julio de 1939 (54). En Córdoba la primera lista de encartados se remite al Boletín de la Provincia en diciembre de 1939. Pero en esta última los procedimientos de Incautación de Bienes se remontan al verano de 1936 (55). En aquellos lugares que no fueron ocupados por el ejército sublevado hasta el final de la contienda la tarea depuradora comenzaba de cero por lo que el volumen de trabajo era mucho mayor.

A la ingente labor recién iniciada en la provincia de Valencia le sobrevino un contratiempo: el cese prematuro del juez instructor. Por orden del 31 de agosto de 1939 Enrique de Iturriaga cesaba en su cargo (56). De esta forma, las fechas aproximadas de inicio y fin de la actividad de este primer juez se solapan e incluso entran en contradicción. En cualquier caso, el cese en las funciones de este primer juez se produjo con posterioridad a la orden y a la fecha de publicación de la misma en el BOE -31 de agosto y 3 de septiembre respectivamente-. Como se indica previamente, al menos los días 5 y 9 de septiembre se encontraba iniciando actuaciones y ordenando la primera providencia. Igualmente, es probable que algunas diligencias fueran finalizadas por el secretario, lo cual

(51) Orden de Vicepresidencia de 2 de junio de 1939. BOPV de 16 de junio.

(52) ERP contra Juana Mancilla, fondo Valencia, caja 4093/27, ARV.

(53) Véanse los expedientes de Juana Mancilla y Vicente Nalda, iniciados según el propio expediente el 5 y el 9 de septiembre respectivamente. ERP contra Juana Mancilla, fondo Valencia, caja 4093/27, ARV. ERP contra Vicente Nalda, fondo Valencia, caja 4093, ARV.

(54) Állvaro (2006): 179.

(55) BARRAGÁN (2009): 145 y 250-253.

(56) BOPV de 9 de septiembre. 
podría explicar la remisión a nombre de Enrique de Iturriaga de anuncios de incoación al BOPV en la tardía fecha de 18 de septiembre.

La misma orden nombró para sustituirlo a Félix José de Vicente. De nuevo se repiten los obstáculos a la hora de situar el inicio de sus funciones. Según la escasa información contenida en algunos expedientes a mediados de septiembre de 1939 ya se hallaba ordenando providencias (57). Si hubo un lapso de días en los que la jurisdicción de Responsabilidades Políticas en Valencia fue huérfana de juez instructor estos no superarían una semana. No obstante, no es aventurado señalar que probablemente el cambio de titularidad pudo ralentizar el ritmo de la instrucción, entre otros factores, por la adaptación del nuevo titular.

Félix José de Vicente ocupó su cargo hasta la disolución de los Juzgados Instructores Provinciales por la reforma de 1942, salvo pequeños lapsos en los que la documentación nos habla de un juez accidental. No fue el único cambio de personal que pudo perjudicar la dinámica judicial. A finales de febrero de 1940 el BOE anuncia un nuevo cese: el de Adolfo González. Lo sustituyó el hasta ahora secretario suplente, Ángel Cristóbal, quien permaneció también en el cargo hasta 1942. A partir de mediados de marzo de 1940 ya consta Ángel Cristóbal como secretario del juzgado en las listas de encartados enviadas al BOPV.

A este tándem se unió casi simultáneamente otro dúo: el del nuevo Juzgado Instructor Provincial, el número dos. Creado por orden de 15 de diciembre de 1939 por estar «acreditado el excesivo trabajo que pesa sobre el Juzgado Instructor de Responsabilidades Políticas de Valencia». El Tribunal Nacional será el encargado del reparto de tareas entre ambos «y entre los que, en lo sucesivo, puedan crearse» (58). Aunque no se produjo, se dejó la puerta abierta a la creación de más juzgados. Valencia no fue la única provincia donde, dado el volumen de trabajo pendiente, debieron conformarse nuevos Juzgados Instructores. Según las memorias remitidas por tribunales y juzgados, en tres meses los juzgados acumulaban muchos más asuntos pendientes de los que eran capaces de resolver. Los mismos Tribunales Regionales solicitaron la creación de nuevos Juzgados Instructores. En total se crearon 9 más que se sumaron a los 52 ya existentes (59).

Cuatro días después, el 19 de diciembre, Fausto Pérez fue designado juez instructor de este segundo juzgado de responsabilidades políticas de Valencia (60). Ya a principios de enero de 1940 fue nombrado como secretario Ernesto Garrido hasta entonces secretario suplente en Soria (61). De nuevo rastrear el inicio de su actividad nos zambulle en la búsqueda a través de los datos parciales de la documentación conservada y consultable. La primera lista de incoaciones enviada al BOPV sitúa

(57) Véase por ejemplo el expediente de Mariano Verde. ERP contra Mariano Verde, fondo Valencia, caja 4093, ARV.

(58) BOE de 24 de diciembre.

(59) Sobre la formación y dotación del Tribunal Nacional, Tribunales Regionales y Juzgados Instructores Provinciales véase ÁlVARO (2006): 124-132.

(60) Orden de 19 de diciembre de 1939. BOE de 24 de diciembre.

(61) Orden de 8 de enero de 1940. BOE de 11 de enero. 
este inicio en marzo de 1940, tres meses después de la orden que lo creó (62). La importancia de algunas fechas como las órdenes de creación o nombramientos deben ser relativizadas dado que después de las mismas el comienzo de la actividad no es paralelo o simultáneo. Además, presumiblemente el lapso sería mayor al hablar de una dinámica normalizada y, llamémosle así, a pleno rendimiento. Ambos, juez y secretario, ocuparon también sus puestos hasta el cese de personal en Valencia de la jurisdicción especial de Responsabilidades Políticas.

A partir de abril de 1940 ambos Juzgados Instructores compartieron espacio en las últimas páginas del BOPV, las dedicadas a «Administración de Justicia». La mayoría de los anuncios referentes a responsabilidades políticas aparecidos en el BOPV desde 1939 hasta abril de 1945 se refieren a la incoación de expedientes. Son además los que gozan de mayor continuidad en el tiempo. Prácticamente nunca aparecen todos los datos previstos por la ley. La dinámica habitual y que continuará tras la reforma de 1942 son listas y listas de nombres y apellidos, quizás, que no siempre, con la vecindad de los mismos. Esta circunstancia, unida a la escasez de expedientes consultables, impide para Valencia un análisis pormenorizado de la represión económica judicial por localidades o profesiones por ejemplo. Igualmente, la ausencia de la fecha de acuerdo del Tribunal dificulta poder discernir hasta qué punto y cuándo se produjo colapso en esta primera fase del procedimiento -con orden de formar expediente pero sin comenzarse la instrucción-.

Los anuncios de incoación en el BOPV implican el inicio de facto de la instrucción de los expedientes. La orden de proceder podía ser anterior -con diferencia de meses y años-. También lo podía ser la formación del expediente -lo que en efectos «físicos» podría traducirse como ponerle una tapa y ordenarlo junto a los demás pendientes-. Pero no es hasta la primera providencia del juez instructor, en la que se ordenan las tres diligencias mencionadas anteriormente, cuando efectivamente empezaba la instrucción en sí recogida por la ley. Las cifras de inicio de instrucción arrojadas por el BOPV de Valencia hasta la reforma de 1942 son las siguientes:

Cuadro 1. Número de encausados por año contra los que se inició la etapa de instrucción.

\begin{tabular}{|c|c|c|c|c|}
\hline Año (63) & 1939 & 1940 & 1941 & 1942 \\
\hline Encartados & 257 & 1.788 & 4.027 & 338 \\
\hline
\end{tabular}

Fuente: BOPV.HMV y ADV. Elaboración propia.

(62) La fecha de publicación en el BOPV es de 27 de marzo. No aparece día de remisión -solo mes y año-.

(63) En 1939 los anuncios se inician en el mes de septiembre. En 1940 no hay publicación de anuncios de incoación en el mes de noviembre. En 1941 no hay publicación en los meses de 
El cuadro recoge las cifras según la fecha de publicación en el BOPV -no de remisión por parte de los Juzgados Instructores-. El plazo entre la remisión desde el juzgado y la publicación en el BOPV es habitualmente de días o semanas siendo escasas las ocasiones en que el anuncio corresponde a un envío realizado meses antes. Por ello, estas cifras pueden contener un pequeño margen de error en los primeros y últimos meses del año -corresponderían a iniciados el año anterior-. Igualmente, las cantidades se refieren a número de encartados y no de expedientes -la mayoría colectivos- con el fin de reflejar mejor el volumen y el impacto humano de la represión económica.

Las cifras difieren notablemente de los datos sobre expedientes tramitados suministrados por los propios Juzgados Instructores y recogidos por Manuel Álvaro. Según estas referencias en la provincia de Valencia se habrían incoado hasta octubre de 1941 un total de 11.074 expedientes -el volumen de encausados sería considerablemente mayor-. El desfase es evidente: el BOPV publicó el preceptivo anuncio de incoación contra 6.072 encartados entre 1939 y 1941 -año completo-. ¿Por qué? Bien pudieron hincharse los datos remitidos. Bien no se anunciaron todas las incoaciones en el BOPV.

O bien porque los números remitidos se refieren a expedientes cuya orden de proceder había llegado al juzgado pero se hallaban pendientes de iniciar la instrucción con la primera providencia -por tanto no hay anuncio en el BOPV. En este caso, la considerable diferencia entre ambas cifras nos conduce a pensar en la enorme acumulación de órdenes de proceder pendientes de ejecutar. El número de incoados según Manuel Álvaro dobla -incluso más si tenemos en cuenta la diferencia numérica entre expedientes y encartados- el de aquellos que podemos asegurar que se habían iniciado las actuaciones de la instrucción.

Las listas en el BOPV fueron creciendo en extensión y publicándose con mayor periodicidad. Más listas y más largas conforme se consolidaban los juzgados provinciales. A partir de abril de 1940 comenzó esta dinámica ascendente que se afianzó a lo largo de 1941. El trabajo conjunto de dos «equipos» aumentó considerablemente la capacidad de la jurisdicción para desatascar el trabajo pendiente en las dependencias de los juzgados provinciales. Al menos el número de expedientes y encartados sobre los que se inició la instrucción creció. Asimismo, otro factor en este despegue fue la consolidación y estabilidad del personal en ambos juzgados.

Pero tras abandonar la montaña de los pendientes, estos expedientes se acumularon en otra: la de aquellos que se hallaban en fase de instrucción. Bien a la espera del cumplimiento de alguna diligencia, bien a la espera de remitirse al Tribunal Regional. El afán represivo desbordó los juzgados y aquel sencillo y rápido proceso de instrucción resultó no ser tal. Los jueces se encontraron con

mayo, junio y julio. Finalmente, para el año 1942 la cifra se refiere a los anuncios de incoación publicados hasta el mes de marzo (los últimos remitidos por los Juzgados Instructores Provinciales). No hay en enero. 
verdaderos problemas a la hora de poder ejecutar los preceptos marcados por la ley y, aún peor, consumarlos en el periodo establecido. De hecho, no se cumplieron. Las providencias chocaron con diferentes obstáculos que imposibilitaron, por un lado, cumplir los plazos previstos. Por otro, cumplir las mismas diligencias.

En primer lugar, la localización de los encartados y encartadas no resultó siempre una tarea sencilla. No se les facilitaba el paradero con la consiguiente pérdida de tiempo. Si se encontraban cumpliendo condena, el establecimiento penitenciario donde se hallaban no solía constar como dato en la información procedente del Tribunal Regional. En consecuencia debían solicitar esta información a la Auditoría de Guerra o al Juzgado Militar competente con el fin de remitir las prevenciones previstas por la ley. Por conducto del director del presidio llegaba a los encartados la noticia de que se hallaban incursos en un procedimiento por responsabilidades políticas.

Si se hallaban fuera de la cárcel localizarlos era más complicado. Entonces, los jueces iniciaban un intercambio de correspondencia con diferentes autoridades. No es extraño que no residiesen donde constaba en los distintos registros y se hallasen cerca de familiares o en alguna capital de provincia. Una vez encontrados, el alcalde, juez municipal o juez de paz se encargaba de hacer cumplir lo previsto por la ley. Todo este proceso de búsqueda, correspondencia, localización, notificación y envío de la preceptiva relación jurada de bienes podía alargarse más del mes previsto para la instrucción del expediente.

Recabar los informes políticos y/o socioeconómicos también se alargó más de lo esperado. Las autoridades debían emitirlos y remitirlos urgentemente en el plazo de cinco días. Sin embargo, lo normal fue que estos se demorasen. También que el juez se viese obligado a reiterar la petición, esperar la llegada de los más rezagados para concluir la instrucción o, incluso, remitir el expediente a falta de alguno de ellos. Fernando Peña y Manuel Álvaro interpretan la tardanza atendiendo a la saturación de las autoridades locales, quienes debían confeccionar informes y avales para múltiples trámites. Fernando Peña agrega que la ley no tuvo en cuenta las dificultades de comunicación con algunas zonas. La posible resistencia de una parte a participar en los resortes represivos sería minoritaria (64).

Una montaña de expedientes se hallaba pendiente de cumplir alguna diligencia -y por tanto en plena fase de instrucción- al aprobarse la reforma de 1942. En junio de ese año, los expedientes recogían la última providencia de los jueces instructores provinciales de responsabilidades políticas: «De conformidad a lo dispuesto en la Ley de 19 de febrero último, y lo ordenado por la Superioridad, suspéndase la tramitación de este expediente y remítase a la Jurisdicción ordinaria para su continuación» (65).

(64) Álvaro (2006): 135-136. PeÑa (2010): 79.

(65) En este caso la orden es del juez número 1, Félix José de Vicente. ERP contra Cándida Alapont, fondo Valencia, caja 4080/1, ARV. 
La formación de otro juzgado y la estabilidad de dos «equipos» no fueron suficientes. La montaña pasó a la justicia ordinaria. Los Juzgados de Primera Instancia anunciaron la incoación de expediente en el BOPV contra 6514 encartados entre agosto de 1942 y abril de 1945. Una cifra sensiblemente superior a la del periodo anterior (6.410) (66). Una parte serían órdenes de la Audiencia que no había realizado aún el Tribunal Regional. De otra parte ya se había ordenado la formación pero nunca se habían iniciado las diligencias previstas por la ley para su instrucción. Otro montante que sumar a la cifra anterior es el de aquellos que pasaron a los Juzgados de Primera Instancia sin haberse concluido la instrucción del expediente. Una última suma correspondería a aquellos que se hallaban pendientes de fallar.

El 30 de junio de 1942 se cesó al personal de la jurisdicción especial (67). Habían fracasado en la aplicación de la ley, si bien el mismo texto legislativo es una de las causas que lo explica. No hay un momento concreto para el colapso, ni cronológico ni en cuanto a fase del procedimiento se refiere. La acumulación y la consiguiente montaña se produjeron gradualmente pendientes de una u otra cosa. En los juzgados se amontonaron los pendientes de iniciar de facto y aquellos que estaban en plena fase de instrucción. Ya en diciembre de 1939 el desfase entre orden de incoación e inicio efectivo de la instrucción es de meses. En 1940 y 1941 Félix José de Vicente está incoando expedientes cuya orden de proceder se remonta a finales de 1939. Otra montaña la conformaron en los juzgados aquellos que se hallaban pendientes de finalizar la instrucción. Los plazos del texto legislativo eran quiméricos. Más si tenemos en cuenta la obstaculización en su cumplimiento que implicaban cuestiones como no disponer del paradero del encartado.

\section{CONSIDERACIONES FINALES: LA CADENA DEL COLAPSO}

En apenas dos años la jurisdicción de Responsabilidades Políticas se había convertido en un problema de no poca importancia. Según las investigaciones con las que contamos la aplicación de la Ley de Responsabilidades Políticas por la jurisdicción especial creada ex profeso fue un fracaso en términos de eficacia en la tramitación de expedientes. La ley y sus organismos competentes crearon una montaña de causas que no eran capaces de resolver con rapidez -tampoco

(66) La cifra para la segunda etapa de la LRP (a partir de la reforma de 1942) ha sido extraída también a partir de los anuncios de incoación publicados en el BOPV. Estos anuncios de incoación en el BOP arrojan la suma de 12.924 encausados por posible responsabilidad política entre el verano de 1939 y abril de 1945 . No obstante, no es este un cómputo total -si es que puede haberlo- sino mínimo y aproximado. Debemos contar, entre otros factores, con el margen de error humano o con la necesidad de seguir introduciendo correctores y cruzando vías de contabilización.

(67) Orden de 30 de junio de 1942. BOE de 5 de julio. 
lo fue después la justicia ordinaria-. La provincia de Valencia no fue una excepción, si bien debemos tener en cuenta además la inexistencia previa de Incautación de Bienes, la tardía ocupación y el volumen de la represión de posguerra en este territorio.

La cadena que llevaba al colapso comenzaba en el contenido de la misma ley. Su afán represivo unido a la indeterminación, la ambigüedad y la vaguedad que caracterizan, al artículo $4 .^{\circ}$, colocaban a un gran número de personas en el centro de la diana. Los eslabones continuaban a lo largo de todo el proceso de aplicación del texto legislativo. El margen de interpretación que permitía la ley fue empleado con afán vengativo, rozando lo absurdo, por parte del Tribunal Regional y/o los denunciantes e informantes. Ello generó un cúmulo de causas que chocó frontalmente con un procedimiento quimérico en la práctica. Y con la incapacidad de los Juzgados Instructores Provinciales para resolverlo, aún menos teniendo en cuenta los contratiempos en su composición que ralentizaron la dinámica judicial normalizada.

En la provincia de Valencia se creó un segundo juzgado. El trabajo de dos «equipos» estables influyó en el ritmo de trabajo de la jurisdicción, haciendo crecer notablemente la capacidad de avanzar en la resolución de todo el trabajo pendiente. Pero no fue suficiente. Tampoco se les facilitó la ingente tarea. Los juzgados se vieron obligados a perder un tiempo valiosísimo con disquisiciones que podían llegar hechas -la localización de los encartados-; también tramitando expedientes contra posibles encartados que contenían errores graves de información personal o que fueron imposibles por no tratarse de nadie en concreto. El resultado: los expedientes se acumularon formando una montaña en las dependencias de estos juzgados. Bien pendientes de iniciarse la instrucción o bien en pleno proceso.

Indagar en los eslabones de esta cadena, en los factores o causas que pueden explicar el rápido colapso de la jurisdicción y su fracaso en términos de eficacia ha sido el objetivo de estas líneas (68). Igualmente, hemos tratado de aproximarnos a los momentos del colapso analizando fundamentalmente dos fases, aquellas en las que entendemos que la parálisis y la montaña pudieron ser mayores: los acumulados pendientes de iniciar de facto la instrucción y aquellos que se encontraban en plena fase de instrucción a la espera de cumplir todas las diligencias previstas por la ley. El trabajo desbordó a los Juzgados Instructores. Tras la reforma de 1942, pese a la racionalización del procedimiento y los sobreseimientos previstos por distintos supuestos, tampoco los Juzgados de Primera Instancia pudieron resolver el problema con la premura deseada.

(68) No se quiere hacer referencia a un discutible fracaso en la eficacia represiva de la Ley de Responsabilidades Políticas y su aplicación. Es más, la falta de eficiencia para resolver y el alargamiento pudieron hacer aumentar la capacidad y eficacia represiva de esta jurisdicción especial como mecanismo de control que generó todo un sinfín de efectos no contables. 


\section{BIBLIOGRAFÍA}

Aguado, A. y Verdugo, V. (2011). Las cárceles franquistas de mujeres en Valencia: castigar, purificar y reeducar. Studia historica. Historia Contemporánea, 29, 55-85.

Álvaro, M. (1990). Los militares en la represión política de posguerra: la jurisdicción especial de Responsabilidades Políticas hasta la reforma de 1942. Revista de Estudios Políticos, 69, 141-162.

- (2006). «Por ministerio de la Ley y voluntad del Caudillo». La Jurisdicción Especial de Responsabilidades Políticas. Madrid: CEPC.

- (2012). Delitos políticos, pecados democráticos. En J. Aróstegui (coord.). Franco, la represión como sistema (pp. 60-106). Barcelona: Flor del Viento.

Barragán, A. (2009). Control social y responsabilidades políticas: Córdoba (19361945). Córdoba: El Páramo.

Cano, J. (1985). La política judicial del régimen de Franco (1936-1945). Madrid: Ministerio de Justicia.

Carrillo, M. (2007). La legislació repressiva de la dictadura franquista en el periodo 1939-1959. En P. Pagés (dir.). Franquisme i repressió. La repressió franquista als Països Catalans (pp. 75-102). Valencia: PUV.

Cenarro, A. (2014). La Ley de Responsabilidades Políticas. En J. Casanova y A. Cenarro (eds.). Pagar las culpas. La represión económica en Aragón (1936-1945) (pp. 23-43). Barcelona: Crítica.

Corretgé, F., Farré, J., Mir, C. y Sagués, J. (1997). Repressió económica i franquisme: l'actuació del Tribunal de Responsabilitats Polítiques a la província de Lleida. Barcelona: Publicacions de l'Abadia de Montserrat.

Gabarda, V . (2007) [1993]. Els afusellaments al País Valencià (1938-1956). Valencia: PUV.

García i Fontanet, A. (2000). Un aspecte de la repressió franquista de postguerra: La Ley de Responsabilidades Políticas. En M. Risques, F. Vilanova y R. Vinyes (coords.). Les ruptures de l'any 1939 (pp. 129-152). Barcelona: Publicacions de l'Abadia de Montserrat.

Gil, P. (2004). La noche de los generales. Militares y represión en el régimen de Franco. Barcelona: Ediciones B.

Langarita, E., Moreno, M. y Murillo, I. (2014). Las víctimas de la represión económica en Aragón. En J. Casanova y A. Cenarro (eds.). Pagar las culpas. La represión económica en Aragón (1936-1945) (pp. 41-96). Barcelona: Crítica.

Langarita, E. (2014). «Si no hay castigo, la España Nueva no se hará nunca». La colaboración ciudadana con las autoridades franquistas. En J. Casanova y A. Cenarro (eds.). Pagar las culpas. La represión económica en Aragón (1936-1945) (pp. 145173). Barcelona: Crítica.

Moreno, F. (1999). La represión en la Posguerra. En S. Julià (coord.). Víctimas de la Guerra Civil (pp. 316-322). Madrid: Temas de Hoy.

Moreno, N. (2014). «Por el bien de la Patria y de la Justicia». Denuncias e informes de las autoridades aragonesas. En J. Casanova y A. Cenarro (eds.). Pagar las culpas. La represión económica en Aragón (1936-1945) (pp. 119-142). Barcelona: Crítica. 
Murillo, I. (2014a). «Ni moral, ni justo, ni legal, ni humano». Resistencias civiles al franquismo. En J. Casanova y A. Cenarro (eds.). Pagar las culpas. La represión económica en Aragón (1936-1945) (pp. 227-253). Barcelona: Crítica.

(2014b). «A Vuestra Excelencia con el mayor respeto y subordinación». La negociación de la Ley «desde abajo». En J. Casanova y A. Cenarro (eds.). Pagar las culpas. La represión económica en Aragón (1936-1945) (pp. 203-226). Barcelona: Crítica.

Peña, F. (2010). El precio de la derrota: la Ley de Responsabilidades Políticas en Castellón (1939-1945). Castellón: Publicaciones UJI.

Sánchez, G. (1984). Las responsabilidades políticas en la posguerra española. El partido judicial de Monóvar. Alicante: Universidad de Alicante. 